This item was submitted to Loughborough's Research Repository by the author.

Items in Figshare are protected by copyright, with all rights reserved, unless otherwise indicated.

\title{
Investigating offering of vegetables by caregivers of preschool age children
}

PLEASE CITE THE PUBLISHED VERSION

http://dx.doi.org/10.1111/cch.12400

\section{PUBLISHER}

(c) Wiley

\section{VERSION}

AM (Accepted Manuscript)

\section{PUBLISHER STATEMENT}

This work is made available according to the conditions of the Creative Commons Attribution-NonCommercialNoDerivatives 4.0 International (CC BY-NC-ND 4.0) licence. Full details of this licence are available at: https://creativecommons.org/licenses/by-nc-nd/4.0/

\section{LICENCE}

CC BY-NC-ND 4.0

\section{REPOSITORY RECORD}

Holley, Clare E., Claire V. Farrow, and Emma Haycraft. 2019. "Investigating Offering of Vegetables by Caregivers of Preschool Age Children". figshare. https://hdl.handle.net/2134/22272. 
1

2

3

4

5

6

7

8

9

10

11

12

* Address correspondence or requests for reprints to: Dr. Emma Haycraft, School of Sport,

13 Exercise and Health Sciences, Loughborough University, Loughborough, Leicestershire,

14 LE11 3TU, UK. Tel. +44(0)1509 228160. Email. E.Haycraft@lboro.ac.uk

15

16 Running head: Investigating offering of fruits and vegetables

17

18 Acknowledgements: We would like to thank Dr Hilary McDermott for her advice on

19 qualitative analysis.

20 Conflict of interest: None to report.

21 Funding: Clare Holley was supported by a PhD studentship from Loughborough University, 22 UK.

23 Accepted for publication in Child: Care, Health and Development on 1 August 2016.

24 Reference as: Holley, C.E., Farrow, C., \& Haycraft, E. (in press, 2016). Investigating offering of 25 vegetables by caregivers of preschool age children. Child: Care, Health and Development. 
Abstract

28 Background: Research into the methods which caregivers use to encourage children to eat vegetables is limited, with minimal evidence about what the barriers are to offering these foods. Vegetable consumption in children is typically low and so gaining information on these factors is vital in order to develop further caregiver-centred interventions to increase children's vegetable consumption. This study aimed to investigate the methods caregivers use to offer vegetables to preschool aged children, as well as the factors which influence whether and how caregivers present vegetables to their children.

Method: Seventeen caregivers with a preschool aged child participated in focus groups to assess these questions.

37 Results: Thematic analysis indicated that caregivers use a range of methods to offer their children vegetables, with these methods falling into three broad categories: behavioural/active methods, passive methods, and food manipulations. Influences on caregiver offering which emerged from the focus groups formed four categories: information, cost, parent factors, and child factors.

Conclusions: Together with large scale quantitative data, this information can be used to shape future interventions aiming to increase children's vegetable intake as well as to tailor advice given to caregivers striving to achieve a healthful diet for their children.

47 Key words: Caregiver offering, vegetable, barriers, feeding, consumption, child 
Investigating offering of vegetables 3

51 Vegetables are important for health (e.g., Maynard, Gunnell, Emmett, Frankel, \& Davey 52 Smith, 2003) but are under eaten by children (Lennox, Olson, \& Gay, 2011), particularly preschool children (Lennox et al., 2011). It is known that simply providing foods for children does not guarantee that they will be eaten. As such, investigating the methods which caregivers use to offer vegetables to their children and the factors that can influence caregiver offering is imperative in order to tailor advice on achieving healthful diets in young

57 children.

58

Previous quantitative research (e.g., Musher-Eizenman \& Holub, 2007) has revealed that caregivers use a range of methods to encourage children's food consumption. Some feeding practices, such as modelling and use of rewards, have been shown to be successful for increasing children's consumption of vegetables (e.g., Holley, Haycraft, \& Farrow, 2014; Remington, Anez, Croker, Wardle, \& Cooke, 2012; Wardle et al., 2003), as well as for encouraging acceptance when introducing novel fruits (Blissett, Bennett, \& Donohoe, 2012). However, other more controlling feeding practices, such as use of pressure to eat, seem to be counterproductive (e.g., Galloway, Fiorito, Lee, \& Birch, 2005; Galloway, Fiorito, Francis,

67 \& Birch, 2006). Research using measures such as the Comprehensive Feeding Practices

68 Questionnaire (CFPQ; Musher-Eizenman \& Holub, 2007) provides invaluable information on 69 the range of feeding practices used by caregivers. However, such measures have been developed by researchers and clinicians, with minimal input from caregivers. Furthermore,

71 the nature of such questionnaire research prevents the identification of other practices, that aren't assessed in these measures but that are potentially used by caregivers. For these reasons, research involving caregivers to explore the practices which they use to feed children is of interest. 
76 Researchers have begun to use qualitative methods to examine a wider variety of the

77 methods caregivers use to get their children to eat. This has included exploring the use of

78 parental mealtime practices to encourage children's eating (Koivisto \& Sjödén, 1996),

79 parental strategies for managing their children's intake of snack foods (Corsini, Wilson,

80 Kettler, \& Danthiir, 2010), feeding practices used to influence children's food likes and

81 dislikes (Casey \& Rozin, 1989; Russell, Worsley, \& Campbell, 2015), and the barriers which

82 caregivers perceive to establishing healthy child eating behaviours as well as the strategies

83 they use to promote healthy eating (Nepper \& Chai, 2016). In a study by Moore, Tapper and

84 Murphy (2007), mothers of 3 to 5 year old children reported using modelling to encourage

85 consumption of familiar foods and introduce novel foods. Mothers also reported using

86 pressure in the form of assertiveness and contingent rewards (such as dessert or television

87 watching) to encourage consumption, but not to introduce novel foods. In a similar study by

88 Russell et al. (2015) it was found that parents of 2 to 5 year olds reported using a diverse

89 range of behaviours to alter children's food preferences; behaviours which differed in their

90 effectiveness. Although potentially applicable to vegetable consumption, parents were not

91 specifically interviewed on the strategies they employ in relation to encouraging their child's

92 consumption of vegetables in Russell et al.'s study. Given that eating habits established

93 early in childhood track through childhood and into adulthood (e.g., Farrow \& Blissett, 2012;

94 Mikkilä, Räsänen, Raitakari, Pietinen, \& Viikari, 2007), increasing our understanding of how

95 best to promote offerings of vegetables early in childhood is a logical step to help increase

96 vegetable intake during early childhood. By increasing vegetable consumption among this

97 age group, life-long benefits of a healthful diet including vegetables can be maximised.

99 Previous research in this field has been conducted with older children by Kirby, Baranowski, 100 Reynolds, Taylor, and Binkley (1995), with a particular focus on how influences on vegetable 101 consumption differ according to socio-economic status (SES). In contrast to higher SES 102 families, families in the lower SES groups had very few fresh fruits and vegetables available 103 in the home, with these parents rarely providing their children with fruits and vegetables in 
104 their pre-cut form. Children across all SES groups reported thinking of vegetables as

105 "grown-up" foods, which taste "nasty" (Kirby et al., 1995). Although of interest, the findings of 106 this research are not necessarily transferable to caregivers of younger children, who are 107 likely to be less autonomous and whose caregivers have a much greater impact on their 108 eating behaviour at this age (Birch, Savage, \& Ventura, 2007). Furthermore, this research 109 does not delineate between fruits and vegetables, for which there may be distinct influences 110 on consumption. Here, detailed further examination of the methods caregivers of preschool 111 age children use specifically in relation to their child's vegetable consumption is warranted.

113 To be useful, advice given to caregivers on increasing vegetable consumption must be in

114 line with the current feeding practices used by the general population, or address recommendations that are not widely used currently. With this in mind, the present study

116 aims were to build on previous research by using a qualitative approach to investigate the 117 particular methods caregivers use to present their preschool children with vegetables, as 118 well as the perceived barriers to offering their child vegetables.

\section{Method}

\section{Participants}

122 Seventeen primary caregivers with a preschool age child participated in the study, none of 123 whom had children which had been hospitalised for feeding problems. Two caregivers were 124 fathers, 14 were mothers and one was a grandmother. Mean child age was 34.9 months (SD 12.23, range 21 to 59 ) and mean caregiver age was 37.5 years (SD 5.81, range 24 to 51 ).

126 Caregivers were predominantly of White/Caucasian ethnicity $(n=14)$, with two caregivers 127 identifying as mixed race and one as of Chinese ethnicity. Half of the caregivers in this study were educated to university level or higher $(n=9)$ while the other half were non-university 129 graduates $(\mathrm{n}=8)$. 
Investigating offering of vegetables 6

\section{Procedure}

133 Full ethical clearance for this study was obtained from Loughborough University Research

134 Ethics Committee.

135

136

Recruitment

137 Participants were recruited from the East Midlands area of the UK using posters which were

138 placed at toddler groups in Leicestershire as well as on online University noticeboards and in

139 University staff common areas. The study was also advertised in two local Leicestershire

140 newspapers; the Leicester Mercury and Loughborough Echo.

142 Focus groups

143 Written informed consent was obtained from all participants before the onset of the study,

144 with participants fully advised of their right to withdraw at any point. The focus groups were

145 conducted at Loughborough University. Focus groups were run until data saturation was

146 reached (i.e. until no new material was being generated). Five focus groups were conducted.

147 Although these groups comprised a small number of caregivers, all group members were

148 active participants and discussion flowed freely throughout each of the sessions. Three of

149 the groups comprised caregivers recruited using a poster with the tagline 'Do you have a

150 child aged 2-4?' with the description 'we'd love to hear about your experiences of getting

151 your child to eat fruits and vegetables, both good and bad', while two further groups

152 comprised caregivers recruited via a poster with the tag line 'Do you have a 2-4 year old who

153 doesn't like vegetables?' and the description 'We'd love to hear about your experiences of

154 trying to get your child to eat vegetables'. This second set of focus groups was run to ensure

155 that the methods of offering vegetables used by caregivers of a child who refuses/avoids

156 eating vegetables were adequately covered, as recent government statistics suggests that

157 UK children's consumption of vegetables is half that of fruit (Public Health England \& Food

158 Standards Agency, 2014). 
160 All focus groups were facilitated by one moderator $(\mathrm{CH})$ and the sessions were digitally

161 recorded. The moderator used a set of open ended and closed questions written by the 162 research team, which were derived from a thorough review of the relevant literature. These 163 questions aimed to address two main research questions: (1) What methods do caregivers 164 use to encourage their children to eat vegetables?; (2) What factors influence how and 165 whether caregivers present vegetables to their child? Each of these research questions was 166 addressed via a number of questions within the focus groups (see Table 1). After the full set 167 of questions had been covered, caregivers were asked to complete a short demographic 168 questionnaire, including questions about parent and child age, ethnicity, and whether the 169 child had been hospitalised for feeding problems. 
171 Table 1: List of main questions (and research questions) answered within the focus groups What methods do caregivers use to encourage their children to eat vegetables?

Do you give your child vegetables - either within meals or as a snack?

How do you go about this?

Do you offer the same vegetable another time/again if it is rejected?

If your child rejects a vegetable, what do you do next time?

If you are offering a vegetable again, after it has been rejected, does the way you offer the vegetable change or stay the same?

Do you offer your child vegetables that you don't like yourself?

Do you think these methods that you use to encourage vegetable consumption work?

Which methods don't work?

\section{What factors influence how and whether caregivers offer vegetables?}

Are the methods you use to encourage your child to eat vegetables methods which you have planned to use?

Have the methods you use changed since you first became a parent?

(If yes) Why did the methods you use change?

What makes you choose a method?

What would stop you from (re)offering a vegetable?

When do you stop offering a vegetable?

Why do you stop offering a vegetable?

How long or how many times do you keep offering a rejected vegetable for?

If you have more than one child, do you use the same methods of offering with all of your children?

(If not) Why not?

Does/has the way your child reacts shape(d) the methods you use? 
174 Analysis

175 All focus group recordings were transcribed verbatim by the researcher $(\mathrm{CH})$. Although data

176 were collected in relation to fruit and vegetables, only responses relating to vegetable

177 consumption are analysed and reported on here, in line with the study aims. Transcribed

178 data were initially analysed as two separate groups; group one comprised those caregivers

179 recruited purely on the premise of talking about their experiences with their child and

180 vegetables, and group two comprised the focus groups involving caregivers who were

181 recruited on the basis of having a child who didn't like vegetables. However, as no

182 differences were identified in terms of caregivers' responses, results are presented for the

183 whole sample.

184

185 Data were analysed using thematic analysis and following the steps outlined by Braun and

186 Clarke (2006). Initially, after checking the transcripts against the original recordings, all

187 transcripts were read and re-read to fully immerse the researcher $(\mathrm{CH})$ in the data. During

188 this phase, primary thoughts and concepts for later coding were noted. Once the researcher

189 was fully familiar with the data, the process of coding themes and subthemes was

190 undertaken. Initially, interesting features within the data were assigned codes which

191 meaningfully described something of the subject. Next, the full list of codes for the transcripts

192 was collated and sorted into groups representing potential themes. These groups of codes

193 were then collated, through a recursive process of combining and separating groups. This

194 resulted in an organised set of themes; all of which were distinct from each other whilst

195 sitting together in a meaningful way. Both inductive and deductive methods were adopted,

196 allowing themes to be applied from the questions asked as well as new themes to be

197 identified within the transcripts. Themes were assessed using a semantic approach, where

198 themes are identified within the explicit meaning of the data, and not by examining the latent

199 underlying features of these themes, resulting in a rich description of the data set (Braun \&

200 Clarke, 2006). To facilitate reflection and reconciliation of the themes identified, discussion of

201 the coded items was held within the research team. The other members of this team had not 
202 been involved in the focus groups, nor had they read the full transcripts of the groups. These

203 discussions were used to qualify the trustworthiness of the analysis, in combination with a

204 second researcher (CF) performing an analysis on $20 \%$ of the transcripts. This method of

205 assessing trustworthiness of the analysis has been widely used and is acknowledged as

206 appropriate for such a thematic analysis (Yardley, 2008).

207

208

\section{Results}

209 Descriptive statistics

210 A total of five focus groups were conducted, with a mean duration of 38:42 (minutes:seconds)

211 (SD 13:09, range 20:10 to 53:18).

212

213 Thematic analysis

214 It was expected that the two different recruitment posters would result in recruiting two

215 distinct groups of caregivers, for which two separate thematic analyses would be conducted

216 allowing for examination of convergence and divergence. However, after analyses indicated

217 a lack of divergence between the two groups of transcribed data, and following consultation

218 with an experienced qualitative researcher, the two groups were collapsed and analyses are

219 reported as one group. Thematic analysis revealed three main themes surrounding methods

220 of offering vegetables to children, and four main themes around the influences on caregiver

221 offering of vegetables. These are presented in Figure 1. 


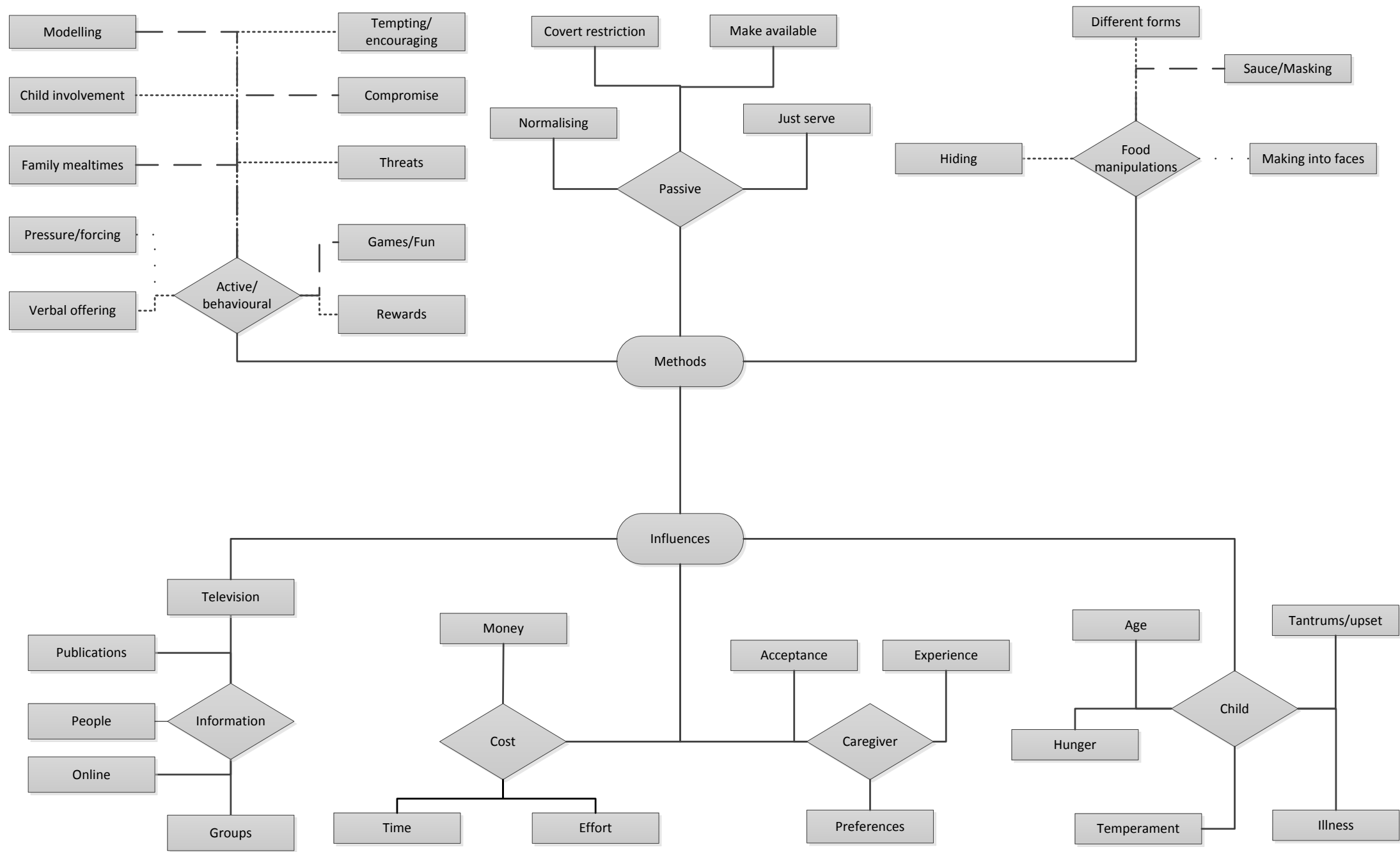

224 Figure 1. Map of themes surrounding parental methods of presenting vegetables to their child as well as the influences on vegetable exposure. 
Methods of presenting vegetables

227 Three major themes reflecting ways of offering emerged from the focus groups, indicating 228 that caregivers use three primary types of methods when presenting vegetables to their 229 children; behavioural/active methods, passive methods, and food manipulations.

\section{Behavioural/active methods}

232 These were methods which relied on specific caregiver-child interactions or behaviours in 233 relation to the caregiver's presentation of vegetables (see Figure 1). Caregivers reported 234 several behavioural/active methods as being successful for getting their child to eat vegetables; the first of these was modelling. Examples of modelling ranged from caregivers eating in front of their children and putting vegetables on their own plates, to caregivers stating how yummy foods were while they ate, encouraging partners to eat vegetables in front of the child, as well as using the child's siblings as role models. Games were also described by caregivers as successful for offering vegetables: “I was like 'let's pretend we're eating trees with our broccoli' and she loves it". Caregivers also reported successfully using

241 family mealtimes to encourage their child to eat vegetables, which likely represents another method of modelling: "I find if we eat as a family it is better, because if I'm doing something and give [child] something to eat she sort of, you know, wonders what l'm doing or will mess abouf'. Finally, caregivers reported that using compromise within the meal setting was successful for getting their child to eat vegetables. Typically this was including additional requested items or compromising on the order in which courses of a meal were eaten.

248 A number of behavioural/active methods were reported by some caregivers as being successful and by others as not, or as working on some occasions but not others. One of these methods was verbal offering of vegetables to their child "'do you want to try one of these peas?". Some caregivers also acknowledged trying to tempt or encourage their child

252 to try and eat vegetables. Caregivers identified sometimes taking this one step further, by 253 offering their child rewards for eating vegetables: "you can have some pudding if you finish 
254 off your X, Y or Z". Rewards took several forms, such as play time, sticker charts or dessert.

255 Child involvement was used by some caregivers, for example letting children choose

256 vegetables in the supermarket or choosing what is served at mealtimes, to growing them at

257 home, as well as helping to prepare and cook them: "we've been growing our own

258 vegetables as well which has helped. Sort of help pick the veg and then help prepare it".

259 Some caregivers reported using pressure or coercion in an attempt to get their child to eat

260 vegetables, but all of these parents agreed that this method does not work: "I've tried 'sit

261 there 'til you've finished' and he can sit there for 3 hours and not eat it, so I don't do that".

262 Finally, some caregivers reported using threats such as not being able to have dessert or 263 having to go to bed if their child didn't eat their vegetables.

Passive methods

266 Caregivers identified a number of passive methods of presenting their children with

267 vegetables (see Figure 1). These included just serving vegetables so that they were put on

268 the child's plate without discussion, and normalising offering through this continued

269 presentation: "but I always make a point of putting it there, because...it's got to be normal

270 hasn't it?". Caregivers also made vegetables available for their child to snack on, whilst

271 removing alternative, more favoured food from the environment in order to encourage the

272 child to eat vegetables as part of their meals: "there's times when he's had some of these-is

273 it Goodies? Those maize-type crispy things, and there's not really anything to them. But if he

274 has those, l've only ever let him have a couple like about a third or a half of a pack in a little

275 bowl, but that will affect how much he eats and how fussy he is later on in the day".

Food manipulations

278 Caregivers reported manipulating vegetables in a variety of ways in order to get their child to

279 eat them (see Figure 1). Several caregivers reported using sauces as well as masking

280 vegetables with flavours to get their child to eat them and most caregivers agreed that this

281 was a successful method. Caregivers also reported hiding vegetables within other foods: "I 
282 put carrot in mashed potato and mash it up so it's like mashed potato, and swede so that it's

283 the same consistency as potato", although they were less certain of whether this was a

284 successful method. Presenting the same vegetable in different forms over a period of time 285 was also a method used by caregivers, but they were also uncertain as to whether this was 286 a consistently successful method, with some caregivers commenting that they will "do it a 287 different way if not roast it, or l'll mash it or put it in a cottage pie topping or something. That 288 always goes down well!". Finally, caregivers acknowledged making vegetables into faces, 289 but all caregivers who reported trying this method agreed that it did not work to get their child 290 to eat vegetables: "faces don't work, really. Like you say I do it for my entertainment I think 291 'ooh that'd make a brilliant eye!' (all laugh) I could lay it like this on the plate that looks amazing and it's like...no".

293

Influences on how/when parents present vegetables

Multiple influences on how and when caregivers present their children with vegetables emerged from the focus groups. These were broadly clustered around four main themes:

297 information, cost, parent factors, and child factors.

298

299

\section{Information}

300 Caregivers talked about obtaining information on how to get their children to eat vegetables 301 from a number of sources (see Figure 1). These sources included: books, television and 302 online, support groups, people and social support (e.g., from family members or other 303 parents). Caregivers also commented that the general provision of information for caregivers 304 around getting children to eat vegetables is poor and can be conflicting, for example "I was 305 at a bit of a loss because you don't get much advice from anywhere, I felt, from where I live". 306 
308 Cost was a recurring influence on caregiver offering of vegetables to their children (see

309 Figure 1). This theme can be broken down into three types of cost, the first of which is

310 financial (including food waste). Caregivers also talked about the time taken to prepare and

311 cook vegetables for their children, as well as the effort involved in cooking and coming up

312 with inventive ways of offering vegetables. Although acknowledged by several caregivers as

313 a barrier to repeated presentation, costs did not always lessen or stop caregivers from

314 presenting their children with vegetables which they may not eat: "[child] gets carrots and

315 green beans and broccoli on his plate two or three times a week, and they get thrown in the

316 bin. But they're always on his plate".

Caregiver factors

319 A few caregiver factors which influence whether caregivers present their children with

320 vegetables emerged from the focus groups (see Figure 1). One of these was caregivers'

321 own preferences for vegetables. Here, it varied between caregivers as to whether they would

322 offer their children vegetables which they do not eat themselves: "[Husband] doesn't like

323 cabbage, so I don't buy cabbage just for me or [child]. So, yeah, I suppose [child]'s diet is

324 restricted to what we like really". Caregivers' experiences of feeding vegetables to other

325 children also influenced how and whether they presented their 2 to 4 year old with vegetables: "it changes, I think, from one child to the next because you learn from your first and then try and do it different with the next". This experience altered the methods which caregivers used, as well as caregivers' attitudes towards offering. For example, caregivers with older children reported feeling more relaxed about getting their younger child to eat vegetables: "with [the] first or second child I can imagine it'd be quite stressful, but now I've got to...five, my attitude is well they're not going to die if they don't eat this plate of food". Finally, some caregivers reported developing acceptance to the vegetables their child would

333 and wouldn't eat, or their child's general dislike of these foods: "I'm not sure if we'd

334 persevered with it, it would've had the desired result because I think that ultimately the 
336 one prevented caregivers from offering their child (other) vegetables, or lessened their 337 attempts at offering.

\section{Child factors}

340 There were several child factors identified in the focus groups which influenced caregivers' 341 presentation of vegetables (see Figure 1). One of these was the age of the child, which

342 impacted on the methods which caregivers said they adopted, such as whether they used

343 rewards or disguised vegetables: "a two year old you can do it [hide vegetables] more with

344 say than a four year old". Another child factor was hunger level. Several caregivers

345 explained that they tried to ensure their child was hungry before offering vegetables in an

346 attempt to increase acceptance of them: "I do find that if it's something that they don't

347 particularly want, they can then refuse it if they're not really that hungry...if he's hungry he'll

348 eat the lot, and there's no messing around and it's gone". Caregivers also identified that child

349 tantrums and upset can influence how/when they present vegetables: "normally once they've 350 said no...you're going to have a tantrum on your hands and sometimes it's easier to not deal 351 with it". This seemed to influence caregivers in one of two ways: 1) that if their child became 352 upset that they would stop the episode of presenting a vegetable; or 2) that they would not 353 present vegetables if they thought it may upset their child, as they were concerned about creating greater feeding difficulties for their child: "as much as you're told to try and give your child a balanced diet you're also warned about the dangers of making food a major issue. So you're kind of caught between both". Child temperament was also identified as having an influence on caregivers' offering of vegetables and children's food refusal: "she's very stubborn". Finally, some caregivers reported that they would not reoffer a vegetable if it had made their child unwell, or if their child was already unwell. 
363 The aim of this study was to investigate caregivers' methods of presenting vegetables to 364 their children and the perceived barriers to offering their child vegetables. It was found that caregivers' methods of offering vegetables can be broadly categorised into active/behavioural methods, passive methods, and methods which are based on manipulating the foods being offered. A number of influences on caregiver offering also emerged from the focus groups. These fell into four categories: information, cost, parent 369 factors, and child factors.

371 Caregivers in this study suggested various behavioural/active methods of offering vegetables. Two of these (rewards and modelling) have been the crux of successful parentled interventions aimed at increasing children's acceptance of a disliked vegetables (e.g.,

374 Holley et al., 2014; Remington et al., 2012; Wardle et al., 2003), as well as being observed in 375 successful caregiver offering of novel fruits to their children (Blissett et al., 2012). This is a 376 promising finding, suggesting that such interventions may have good feasibility for 377 caregivers, where the required behavioural methods are in line with current practices used 378 by caregivers. In line with previous literature on parental feeding practices, caregivers suggested using compromise during mealtimes, a demonstration of flexible, authoritative feeding practices (Baumrind, 1968), and unanimously agreed that using more rigid and authoritarian feeding practices, such as pressure, were counterproductive. Indeed, previous

382 literature has found that authoritative feeding practices are associated with higher intake of 383 vegetables (Patrick, Nicklas, Hughes, \& Morales, 2005), so the current findings suggest that practices used by the caregivers in these focus groups to get their children to eat vegetables included some of the more favourable ones. Getting children involved in growing, choosing and preparing vegetables was also rated as a successful behavioural/active method by some caregivers in the current study, or as successful on some occasions, aligning with research demonstrating that involvement via a school gardening programme can increase children's willingness to try vegetables (Morris, Neustadter, \& Zidenberg-Cherr, 2001). 
390 However, involving children in these practices may prove difficult for caregivers who find

391 time constraints to be a barrier to offering their children fruits and vegetables, a point which

392 will be further discussed later on.

393

394 The passive methods (such as normalising the inclusion of vegetables) which caregivers in 395 this study reported using to encourage their children to eat vegetables are likely to reduce 396 neophobic responses in children. By ensuring that vegetables are normally present at 397 meal/snack times, parents are increasing children's familiarity with these foods, where it is 398 known that children's liking is significantly associated with their familiarity with a food (Cooke $399 \&$ Wardle, 2005). Some caregivers in the current study also covertly restricted other less 400 healthy and more highly favoured alternative foods as a way to encourage children to eat 401 meals which include vegetables. This is a practice which has been shown to promote 402 children's fruit and vegetable consumption (Brown, Ogden, Gibson, \& Vogele, 2008). 403

404 In line with previous research, caregivers suggested manipulating food in a variety of ways 405 as being potentially successful for increasing children's consumption of vegetables (Poelman 406 \& Delahunty, 2011; Reimer et al., 2004; Savage, Peterson, Marini, Bordi, \& Birch, 2013). 407 These manipulations included hiding vegetables to increase their child's consumption (such 408 as mashing other vegetables in with potatoes), using sauces, and presenting vegetables in 409 different forms. Although there is some research evidence that hiding vegetables within 410 foods can increase children's consumption of the hidden vegetable (e.g., Spill, Birch, Roe, \& 411 Rolls, 2011), the use of this practice likely misses valuable opportunities for children to 412 develop a liking or willingness to consume vegetables when they are "seen". Because 413 children are unaware of the presence of the vegetables, it is unclear what impact hiding 414 vegetables has on increasing consumption of vegetables when they can be seen (Pescud \& 415 Pettigrew, 2014). Previous research has suggested that preparation methods can influence 416 acceptance of vegetables, particularly in children who like fewer vegetables, given that taste 417 and texture can vary significantly as vegetables are cooked (Poelman \& Delahunty, 2011). 
418 With this in mind, exploring different methods of preparation and presenting vegetables in a

419 variety of forms seems logical for increasing children's consumption. As one of a

420 combination of methods, hiding vegetables may be useful for increasing children's

421 consumption in the short term, while manipulations - such as offering vegetables in a variety

422 of preparations - may promote children's tasting of these foods which, in turn, could

423 potentially result in long-term increases in consumption. It would be of interest to explore

424 caregivers' perceptions of these methods for achieving different outcomes.

426 A number of influences to offering vegetables were highlighted by caregivers in this study.

427 One of these was information about offering vegetables to children. Although caregivers 428 reported obtaining information from a number of sources, caregivers highlighted that 429 information was not only limited but also conflicting, which aligns with previous research (e.g., 430 Mitchell, Haycraft, \& Farrow, 2013). This suggests that the provision of information to 431 caregivers on the importance of offering and reoffering vegetables must be improved.

433 Another barrier to offering was the cost of offering vegetables, whether financial, time, or 434 effort; although some caregivers stated that this would not stop them from reoffering these 435 foods to their children. Research suggests that a diet higher in fruits and vegetables does 436 cost more financially than a diet higher in fats and sweets (Drewnowski, Darmon, \& Briend, 437 2004). For caregivers who have a smaller budget for feeding their children, the repeated 438 food waste resulting from rejection of vegetables would present a bigger barrier to future 439 offering than for caregivers in this study. Providing information to parents on the success of 440 repeated offering of foods, and reassuring them that waste (and the associated cost) need 441 not be long term, may encourage parents to reoffer vegetables in the short term until their 442 child accepts these foods. Parents could also be educated on ways to offer vegetables more 443 cheaply, such as preparing food in bulk (Kilcast et al., 1996), as well as ways in which to 444 reuse refused vegetables for themselves or other children. Although research into time as a 445 barrier to caregivers offering vegetables is limited, previous studies have revealed time to be 
446 a barrier to parents' preparation of meals (Fulkerson et al., 2011; Nepper \& Chai, 2016). One

447 possible solution to time as a barrier to offering may be to educate caregivers on the easiest

448 methods of preparing vegetables, particularly preparing in bulk and in advance of mealtimes,

449 which are methods previously demonstrated by high vegetable consumers (Kilcast et al., 450 1996).

452 Caregivers' attitude towards their child's vegetable consumption also appears to influence 453 offering of vegetables. Some caregivers in this study stated that they had developed a level 454 of acceptance towards their child's refusal of many vegetables and had resolved to accept 455 the selection of foods their child would eat. With this in mind, caregivers who have come to 456 accept their children's food refusal may benefit from better provision of information on the

457 value of persistent offering of disliked foods to children (Cooke, 2007), and also of eating 458 more vegetables in sight of their children (modelling; Palfreyman, Haycraft, \& Meyer, 2014).

460 A number of child factors which influence how and when caregivers offer their child 461 vegetables were also discussed, such as child age, hunger and children getting upset. It emerged that some caregivers would not offer vegetables which their child dislikes if their child became upset when presented with the vegetable for fear of creating greater feeding difficulties. To minimise this fear, advice to caregivers should be tailored to reassure them about the appropriate level of persistence to use when feeding a child, with it known that repeated exposures to disliked foods are necessary for children to accept them (Cooke, 467 2007) and that pressure to eat can result in lowered preference for pressured foods (e.g., 468 Galloway et al., 2005; Galloway et al., 2006). Child age influenced the behavioural method of offering which caregivers' employed. With this in mind, advice given to caregivers about possible methods to encourage consumption of vegetables should include information about

471 which particular methods are the most appropriate for children of different ages. More 472 research in this area seems necessary in order to develop specific advice tailored to child 473 age. 
475 There are multiple strengths to the current study. First, it provides up to date information 476 about the methods caregivers in the UK use to offer vegetables to young children. With it 477 known that children's consumption of vegetables is particularly low, this area is a public 478 health priority. Furthermore, these data are enriched by providing information on the 479 perceived barriers to caregivers offering of vegetables, which could be translated into 480 information for caregivers on how to overcome these barriers. Having said this, this study 481 does have its limitations. First, the employment levels of the participants in this study 482 suggest that this sample is of relatively high SES and, as caregiver methods and particularly 483 barriers to offering may well be different amongst lower SES groups, future research should 484 aim to recruit a more socio-economically diverse sample of caregivers. Moreover, the word 485 'methods' was used throughout the focus group questions which might have prompted caregivers to discuss overt behavioural strategies which they use when offering vegetables,

487 rather than more covert methods. This might explain the dominance of overt methods in the 488 results of this study. Finally, the reflexivity of the caregiver-child interactions at feeding time 489 is impossible to disentangle, and therefore discussion of caregiver and child influences on 490 consumption of vegetables must bear this in mind.

492 This study makes a valuable contribution to research into increasing children's vegetable 493 consumption by providing novel information about the methods used by caregivers, the 494 barriers to offering vegetables and the strategies that caregivers believe are effective. Future 495 research could explore possible differences in the methods used to achieve short term wins 496 versus the methods used to achieve long-term changes in children's consumption of 497 vegetables. It is likely that methods which caregivers employ to increase consumption on 498 individual occasions are different to the methods which caregivers believe are suitable for 499 achieving a longer-term healthful diet. Together, this information can be used to tailor future 500 advice for caregivers who want to achieve a more healthful diet for their child, by taking into 
Investigating offering of vegetables 22

501 consideration the barriers which caregivers experience to help ascertain the most

502 appropriate methods of offering vegetables for them. 
504

505 - Establishing healthy eating behaviours early in life is an important public health 506 priority yet too many children eat too few vegetables.

$507 \quad$ - This study investigated caregiver methods of offering vegetables to young children as 508 well as the barriers to caregiver offering, to try to understand more about ways to 509 support caregivers with increasing children's vegetable consumption.

510 - Common methods which caregivers used to offer vegetables were grouped into three 511 categories: active/behavioural, passive, and food manipulations.

512 - The main barriers to caregivers offering vegetables were: lack of information, cost, 513 and various caregiver and child factors (e.g., temperament or preferences).

$514 \quad$ - These findings are useful for tailoring future interventions and advice for caregivers 515 as part of public health and policy efforts to increase vegetable intake in children and $516 \quad$ promote healthier lifestyles. 
518 Baumrind, D. (1968). Authoritarian vs. authoritative parental control. Adolescence, 3, 255519272.

Birch, L. L., Savage, J. S., \& Ventura, A. K. (2007). Influences on the Development of Children's Eating Behaviours: From Infancy to Adolescence. Canadian Journal of Dietetic Practice and Research : A Publication of Dietitians of Canada, 68(1), s1-s56.

Blissett, J., Bennett, C., \& Donohoe, J. (2012). Predicting successful introduction of novel fruit to preschool children. Journal of the Academy of Nutrition and Dietetics, 112(12), 1959-1967.

Blissett, J., Haycraft, E., \& Farrow, C. (2010). Inducing preschool children's emotional eating: relations with parental feeding practices. The American Journal of Clinical Nutrition, 92(2), 359-365.

Braun, V., \& Clarke, V. (2006). Using thematic analysis in psychology. Qualitative Research in Psychology, 3, 77-101.

Brown, K., Ogden, J., Gibson, E. L., \& Vogele, C. (2008). The role of parental control practices in explaining children's diet and BMI. Appetite, 50, 252-259.

Casey, R., \& Rozin, P. (1989). Changing children's food preferences: parent opinions. Appetite, 12, 171-182.

Cashdan, E. (1998). Adaptiveness of food learning and food aversions in children. Social Science Information, 37(4), 613-632.

Cooke, L. J. (2007). The importance of exposure for healthy eating in childhood: a review. Journal of Human Nutrition and Dietetics: The Official Journal of the British Dietetic Associationhe Official Journal of the British Dietetic Association, 20(4), 294-301.

Cooke, L. J., \& Wardle, J. (2005). Age and gender differences in children's food preferences. British Journal of Nutrition, 93(5), 741-746. validation of the Toddler Snack Food Feeding Questionnaire. Appetite, 54(3), 570-8.

Drewnowski, A., Darmon, N., \& Briend, A. (2004). Replacing fats and sweets with vegetables and fruits--a question of cost. American Journal of Public Health, 94(9), 1555-9.

Farrow, C., \& Blissett, J. (2008). Controlling Feeding Practices: Cause or Consequence of

Farrow, C., \& Blissett, J. (2012). Stability and continuity of parentally reported child eating Early Child Weight? Pediatrics, 121(1), 164-169. to improve family meals? Journal of Nutrition Education and Behavior, 43(3), 189-93. 
553

554

555

556

557

558

559

560

561

562

563

564

565

566

567

568

569

570

571

572

573

574

575

576

577

578

579

580

581

582

583

584

585

586

587

588

589

590

Galloway, A. T., Fiorito, L. M., Francis, L. A., \& Birch, L. L. (2006). "Finish your soup": counterproductive effects of pressuring children to eat on intake and affect. Appetite, 46(3), 318-23.

Galloway, A. T., Fiorito, L. M., Lee, Y., \& Birch, L. L. (2005). Parental pressure, dietary patterns, and weight status among girls who are "picky eaters". Journal of the American Dietetic Association, 105(4), 541-548.

Holley, C. E., Haycraft, E., \& Farrow, C. (2014). “Why don”t you try it again?' a comparison of parent led, home based interventions aimed at increasing children's consumption of a disliked vegetable. Appetite, 87, 215-222.

Kilcast, D., Cathro, J., \& Morris, L. (1996). Practical approaches to increasing vegetable consumption. Nutrition \& Food Science, 96(5), $48-51$.

Kirby, S. D., Baranowski, T., Reynolds, K. D., Taylor, G., \& Binkley, D. (1995). Children's fruit and vegetable intake: Socioeconomic, adult-child, regional, and urban-rural influences. Journal of Nutrition Education, 27(5), 261-271.

Koivisto, U. K., \& Sjödén, P. O. (1996). Reasons for rejection of food items in Swedish families with children aged 2-17. Appetite, 26(1), 89-103. http://doi.org/10.1006/appe.1996.0007

Lennox, A., Olson, A., \& Gay, C. (2011). National diet and nutrition survey. Headline Results from Years 1 to 4 . Retrieved from http://www.foodafactoflife.org.uk/attachments/8921d124-960e-4f68d4b026f4.pdf

Lytle, L. A., Seifert, S., Greenstein, J., \& McGovern, P. (2000). How Do Children's Eating Patterns and Food Choices Change Over Time? Results from a Cohort Study. American Journal of Health Promotion, 14(4), 222-228.

Maynard, M., Gunnell, D., Emmett, P. M., Frankel, S., \& Davey Smith, G. (2003). Fruit, vegetables, and antioxidants in childhood and risk of adult cancer: the Boyd Orr cohort. Journal of Epidemiology and Community Health, 57(3), 218-225.

Mikkilä, V., Räsänen, L., Raitakari, O. T., Pietinen, P., \& Viikari, J. (2007). Consistent dietary patterns identified from childhood to adulthood: The Cardiovascular Risk in Young Finns Study. British Journal of Nutrition, 93(06), 923-931.

Mitchell, G. L., Haycraft, E., \& Farrow, C. (2013). An “app"ropriate resource? Using mobile apps to provide feeding advice and support to parents. Appetite, 71, 482.

Moore, S. N., Tapper, K., \& Murphy, S. (2007). Feeding strategies used by mothers of 3-5year-old children. Appetite, 49(3), 704-707.

Morris, J., Neustadter, A., \& Zidenberg-Cherr, S. (2001). First-grade gardeners more likely to taste vegetables. California Agriculture, 55(1), 43-46.

Musher-Eizenman, D., \& Holub, S. C. (2007). Comprehensive Feeding Practices Questionnaire: validation of a new measure of parental feeding practices. Journal of Pediatric Psychology, 32(8), 960-72. 
Nepper, M. J., \& Chai, W. (2016). Parents' barriers and strategies to promote healthy eating among school-age children. Appetite, 103, 157-164.

Palfreyman, Z., Haycraft, E., \& Meyer, C. (2014). Development of the Parental Modelling of Eating Behaviours Scale (PARM): links with food intake among children and their mothers. Maternal \& Child Nutrition, 10(4), 617-29.

Patrick, H., Nicklas, T. A., Hughes, S. O., \& Morales, M. (2005). The benefits of authoritative feeding style: caregiver feeding styles and children's food consumption patterns. Appetite, 44(2), 243-249.

Pescud, M., \& Pettigrew, S. (2014). Parents' experiences with hiding vegetables as a strategy for improving children's diets. British Food Journal, 116(12), 1853 - 1863.

Poelman, A. A. M., \& Delahunty, C. M. (2011). The effect of preparation method and typicality of colour on children's acceptance for vegetables. Food Quality and Preference, 22(4), 355-364.

Public Health England \& Food Standards Agency. (2014). National Diet and Nutrition Survey: Results from Years 1, 2, 3 and 4 (combined) of the Rolling Programme (2008/2009 2011/2012). Retrieved from https://www.gov.uk/government/uploads/system/uploads/attachment_data/file/310995/ NDNS_Y1_to_4_UK_report.pdf

Reimer, K., Smith, C., Reicks, M., Henry, H., Thomas, R., \& Atwell, J. (2004). Child-feeding strategies of African American women according to stage of change for fruit and vegetable consumption. Public Health Nutrition, 7(4), 505-12.

Remington, A., Anez, E., Croker, H., Wardle, J., \& Cooke, L. J. (2012). Increasing food acceptance in the home setting: a randomized controlled trial of parent-administered taste exposure with incentives. The American Journal of Clinical Nutrition, 95(1), 72-77.

Russell, C. G., Worsley, A., \& Campbell, K. J. (2015). Strategies used by parents to influence their children's food preferences. Appetite, 90, 123-130.

Savage, J. S., Peterson, J., Marini, M., Bordi, P. L., \& Birch, L. L. (2013). The addition of a plain or herb-flavored reduced-fat dip is associated with improved preschoolers' intake of vegetables. Journal of the Academy of Nutrition and Dietetics, 113(8), 1090-1095.

Spill, M. K., Birch, L. L., Roe, L. S., \& Rolls, B. J. (2011). Hiding vegetables to reduce energy density: an effective strategy to increase children's vegetable intake and reduce energy intake. The American Journal of Clinical Nutrition, 94(3), 735-41.

Wardle, J., Cooke, L. J., Gibson, E. L., Sapochnik, M., Sheiham, A., \& Lawson, M. (2003). Increasing children's acceptance of vegetables; a randomized trial of parent-led exposure. Appetite, 40(2), 155-162.

Yardley, L. (2008). Demonstrating validity in qualitative psychology. In J. A. Smith (Ed.), Qualitative psychology: A practical guide to research methods (pp. 235-251). London: Sage. 